\title{
Leaching of Copper Ores: Effects of Operating Variables
}

\author{
Yousef Mubarak \\ Department of Chemical Engineering, American University of Beirut, Lebanon, ym26@aub.edu.lb
}

\begin{abstract}
Leaching of copper from a Jordanian copper ore has been studied using a stirred batch reactor with hydrochloric acid as the main lixiviant, under the following conditions: temperature $25-45{ }^{\circ} \mathrm{C}$, acid concentration $0.05-0.2 \mathrm{~N}$, particle size $462-1850 \mu \mathrm{m}$, stirring speed of $700-1000 \mathrm{rpm}$, and solid/liquid ratio of $1-4 \mathrm{~g} / \mathrm{L}$. It was found that the rate of leaching of copper ore with hydrochloric acid or sulfuric acid, increases with temperature and acid concentration, while it decreases with increasing particle size. At the same operating conditions, leaching with sulfuric acid gave slightly greater conversion than leaching with hydrochloric acid, particularly at operating conditions of high temperature, high acid concentration, and small ore particle sizes. A maximum copper dissolution of about $87 \%$ can be recovered at a leaching temperature of $45^{\circ} \mathrm{C}, 462 \mu \mathrm{m}$ particle size, $0.2 \mathrm{~N}$ hydrochloric acid, $1.0 \mathrm{~g} / \mathrm{L}$ solid to liquid ratio, and $1000 \mathrm{rpm}$ stirring speed. Keeping all these operating parameters constant while decreasing the hydrochloric acid concentration to $0.05 \mathrm{~N}$ will decrease the copper dissolution to $83 \%$. On the other hand, decreasing the leaching temperature to $25{ }^{\circ} \mathrm{C}$ while keeping the other parameters fixed at $0.2 \mathrm{~N}, 1.0 \mathrm{~g} / \mathrm{L}$ solid to liquid ratio, $1000 \mathrm{rpm}$ stirring speed, and a particle size of $462 \mu \mathrm{m}$ decreases the copper dissolution to $80 \%$.
\end{abstract}

Key words: Leaching, Copper Ore, Lixiviant, Particle Size, Surface Reaction, Pore Diffusion

\section{INTRODUCTION}

Materials are abundantly present and available in nature in the form of ores, which are extracted and undergoes different manufacturing process, one of these processes is leaching [1]. Leaching refers to the extraction of a soluble constituent from a solid by means of a solvent. The process may be employed either for the production of a concentrated solution of a valuable solid material, or in order to free an insoluble solid from a soluble material with which it is contaminated. There are many factors influencing the rate of leaching such as temperature, lixiviant concentration and type, particle size and agitation speed of the fluid-particles mixture [2-5].

Heterogeneous reactions between liquids and solids, play a major role in materials processing industries which encompass a broad range of operations, such as extractive metallurgy. The chemical interactions could involve simple single-step or multistep reactions with or without changes in the volume of the phases and heat effects. The particles themselves could be porous or nonporous or may become porous during the reaction. They may also change their size, and significant alterations in the structure might accompany the chemical reaction[6].

The basic steps when a solid particle reacts with a liquid species may include liquid-phase mass transfer, diffusion inside the pores, absorption of reactants, chemical reaction and desorption of products. Although these steps occur in succession, any one or more of these might be rate limiting [7].There are many variables affecting leaching processes. The first of these variables is the boundary layer around the solid particles, when a solid in contact with a liquid is covered by a stagnant film of liquid through which reactants have to diffuse before they reach the reaction location. This film is called the Nernst's boundary layer, its existence is due to two hydrodynamics factors [8]; the adhesion of the liquid to the surface and the viscosity of the liquid.

The second variable is the fluid velocity, when the process is film diffusion-controlled, for a stirred solid/liquid reaction system, increasing the stirring speed sometimes increases the rate of dissolution or reaction. And the thickness of the boundary layer decreases with increasing speed of stirring. In such case, the rate of reaction can be usually expressed as a function of speed. The rate of reaction, however, does not increase indefinitely with increasing speed of stirring because other factors such as the formation of air pockets in the liquid usually interfere. The third variable is the reaction temperature which plays an important rule because chemical reaction velocity constants are experimentally dependent on temperature according to Arrhenius equation $[9,10]$, also the pore diffusion coefficient depends on temperature according to Erying equation[11]. A diffusion-controlled process is characterized by being slightly dependent on temperature while chemically controlled process is strongly dependent on temperature [12].

Copper is considered as one of base metals in our daily life and has high economic importance. Over $80 \%$ of the primary copper production comes from pyro-metallurgical treatment of copper ores [13-15].In Jordan, copper ores were mined on 
both sides of Wadi Araba since prehistoric times and continued with some interruptions until the early medieval period of history. After at least 2500 years of activity, mining appears to have ceased and the ancient sites were forgotten until almost the $20^{\text {th }}$ century [16]. At the east side of Wadi Araba, the first systematic geological investigations began in 1961. The natural Resources Authority carried out, in collaboration with foreign companies, Bureau de Recherches Geologiques et Minieres (BRGM) [17] and Seltrust Engineering Limited (SEL)[18], a number of studies on the mineral deposits in Jordan. These studies have established the location of many large deposits of copper ores of various compositions. Mineralization in the area is limited to two sedimentary rock units. The first is white fine-Sandstone Unit (WFS), which contain a copper mineralization changing in intensity very rapidly within short distance. The second is dolomite-Limestone-Shale Unit (DLS), in which the manganese and iron-bearing copper minerals are mainly observed on top of and within the uppermost dolomite beds. The main copper minerals associated with the DLS unit are: malachite, chrysocolla, placheite, cuprite, tenorite, atacamite, crednerite $\left(\mathrm{CuO}, \mathrm{Mn}_{2} \mathrm{O}_{3}\right)$ and delafossite $\left(\mathrm{Cu}_{2} \mathrm{O}, \mathrm{Fe}_{2} \mathrm{O}_{3}\right)$. Detailed geological surveys and exploration activities resulted in a total estimate of 60 million tons of copper ore reserves, with an average grade of $1.63 \%$ [17].

There are many studies published in the literature on the leaching of non-Jordanian copper ores using various lixiviant. For example, Madsen et al. [19], developed a shrinking core model to describe the leaching of copper from sulfide ores using acidic ferric sulfate. Bryden [8], studied the leaching of copper from malachite using the ammonium sulfate solution and showed that the mixed kinetics model is suitable for their experimental data. Benner and Roman [20], derived a shrinking core model for the leaching of sandstone malachite ore with $\mathrm{H}_{2} \mathrm{SO}_{4}$. The reaction was controlled by the diffusion of hydrogen ions through the rock. Kuzmanvska et al. [21], applied the mixed kinetics model to the leaching, by percolation method, of low-grade chalcocite-covellite ore using sulfuric acid as lixiviant.Few studies have been done on the leachability of the Jordanian copper ores. The French group BRGM [17] and Seltrust Eng. Ltd. [18] carried out a study into the feasibility of exploiting the copper deposits in Wadi Araba. The study showed that the percentage of acid soluble copper, on the average, is about $70-80 \%$ of the total copper content. A series of bench scale tests was carried out to determine the response of the various samples to sulfuric acid leaching [18]. The first series of tests investigated the vat leaching characteristic: three separate size ranges, $-40+20$ $\mathrm{mm},-20+10 \mathrm{~mm}$, and $-10+2.5 \mathrm{~mm}$, were prepared with sulfuric acid solution. The results showed that, for the coarse size range, copper extraction did not exceed $50 \%$ in 32 hours. The conclusion attained was that it was unlikely in practice that high recoveries by percolation leaching would be obtained from the samples with highly carbonated gangue.A second series of agitation leaching tests was then carried out which investigated size of particles, acid strength and leaching time. The results showed that copper extraction ranging from 3.4 - $22.2 \mathrm{~kg} \mathrm{H}_{2} \mathrm{SO}_{4} / \mathrm{kg}$ copper. Overall conclusions from the agitation leaching tests were that average copper extractions of $75 \%$ would be realistic for the low carbonate samples but only about $50 \%$ for highly carbonated samples. Another series of alternative techniques was then studied in an attempt to improve on the copper extraction, including leaching with $\mathrm{SO}_{2}$ and leaching with ammonia or sulfuric acid after reduction roast. The results showed that only leaching with $\mathrm{SO}_{2}$ increased copper extraction significantly. This method, however, resulted in an uneconomical consumption of sulfur. The above studies on Jordanian copper ores did not present any mathematical models to describe the leaching process. Al-Sayyed [22], however, studied the leaching of copper from a Jordanian copper ore from Wadi Araba in a batch reactor using sulfuric acid solution. He found that the shrinking core model is suitable for fitting his experimental data.

There is scarcity of detailed information on the leachability of the Jordanian copper ores using different lixiviants. The objective of current article is to present the effect of the operating parameters on the leaching process of copper from a Jordanian copper ore, in a batch reactor using hydrochloric acid as the main lixiviant. For comparative purpose, however, some experiments were carried out using sulfuric acid solution. The kinetics and modelling of the leaching process will be presented and discussed in another article.

\section{MATERIALS AND METHODS}

\subsection{Equipment}

The experimental arrangement is shown in figure 1, and it consists of a 1-liter nominal capacity Pyrex glass rounded bottom flask with three necks carrying a thermometer, a stirrer, and a sampling device [23]. The stirrer, made of Teflon, consists of a $25 \mathrm{~cm}$ long shaft of $1 \mathrm{~cm}$ diameter with two $3 \times 0.5 \times 1 \mathrm{~cm}$ blades at its end. The stirrer passes through a glass tube which fits tightly into a rubber stopper, to separate the rotating shaft from it. The stirrer is driven by a variable speed electric motor, IKA-WERK type RW 20, and can give a maximum stirring speed of $1000 \mathrm{rpm}$ without generating excessive vibrations and large temperature rise. The reactor temperature was maintained at the desired temperature within $\pm 0.5^{\circ} \mathrm{C}$ using a stirred water bath, Techne model TU16A.

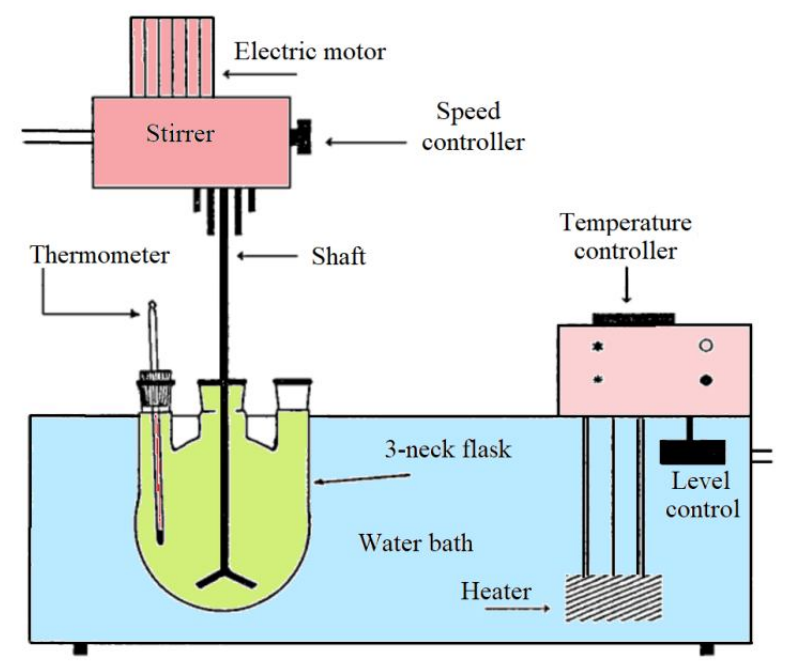

Figure 1: Experimental setup for copper ore leaching 


\subsection{Sampling Device}

The sampling device, figure 2, is calibrated to deliver $5 \mathrm{~mL}$ solution, and has a fritted glass end for filtering the reaction solution. The fritted end stops particles greater than $42 \mu \mathrm{m}$ from passing into the sampling pipette. The sampling device, when connected to a vacuum pump, Gerb. Becker type WB $71 \mathrm{G} 4 \mathrm{~S}$, decreases the time needed for drawing off liquid samples from the reaction flask and allows obtaining five samples during the first two minutes of the reaction. By manipulated the 2-way and 3-way valves to appropriate positions, drawing off or delivery of the sample can be achieved easily [23].
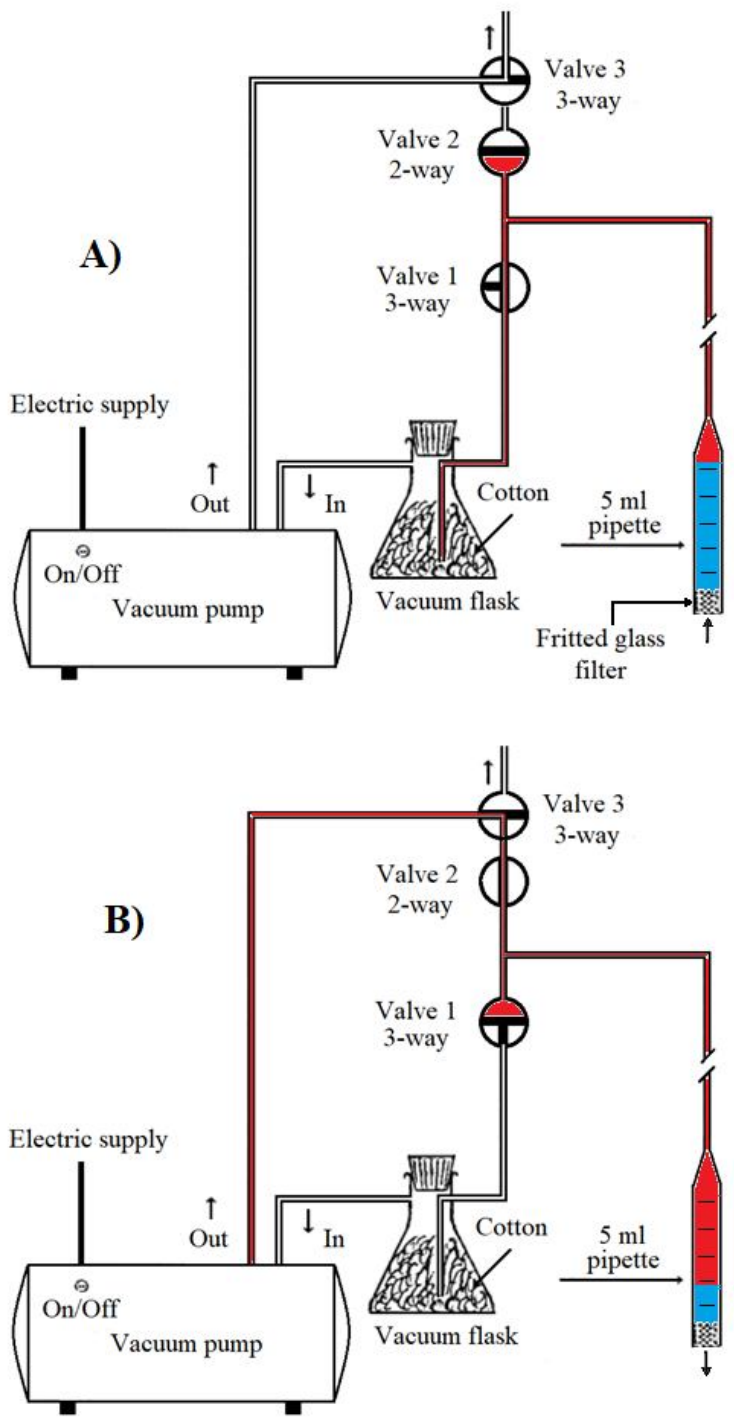

Figure 2: Sampling device arrangement; A) with valves arranged to draw off sample B) with valves to deliver sample

\subsection{Materials Preparation}

A copper ore sample has been supplied by the Natural Resources Authority-Jordan from different locations in Wadi Araba. The ore is whitish beige, medium hard, medium crystalline, and fractured dolomite with copper disseminations. Enough amounts of the ore was grounded using a jaw crusher, Retch model BBIA. The ground sample was then classified to different sizes using standard sieves and a shaker, manufactured by Pascall Engineering. Three sizes of each ore, $-500+425,-1200+1000$ and $-2000+1700 \mu \mathrm{m}$, were chosen for leaching studies. Using the definition of the arithmetic average [24]

$$
D_{P i}=\frac{D_{\text {small }}+D_{\text {large }}}{2}
$$

The average particle sizes used in this study are 462, 1100 and $1850 \mu \mathrm{m}$, respectively. Samples from the chosen ore particles were then analyzed spectrophotometrically for copper and other elements. The method used for the analysis involved digestion of the particles in aqua regia $\left(\mathrm{HNO}_{3}: \mathrm{H}_{2} \mathrm{O}: \mathrm{HCl}\right.$ with a volume ratio of $2: 2: 1$ ), dilution with distilled water and analysis of the solution for the required elements. The analysis was performed using atomic absorption spectrophotometer, SP9 Pye Unicam type. Table 1 shows the average results of the replicate analysis for the copper ore used in the current study. The table also shows the densities of the ores particles.

Table 1: Average analysis of the copper ore used in the study

\begin{tabular}{|l|c|c|c|c|c|c|}
\hline $\begin{array}{l}\text { Particle } \\
\text { size } \boldsymbol{\mu \mathbf { m }}\end{array}$ & $\begin{array}{c}\mathbf{C u} \\
\mathbf{\%}\end{array}$ & $\begin{array}{c}\mathbf{M n} \\
\mathbf{\%}\end{array}$ & $\begin{array}{c}\mathbf{C a} \\
\mathbf{\%}\end{array}$ & $\begin{array}{c}\mathbf{F e} \\
\mathbf{\%}\end{array}$ & $\begin{array}{c}\text { Al } \\
\mathbf{\%}\end{array}$ & $\begin{array}{c}\text { Density } \\
\mathbf{g}_{\mathbf{c m}}\end{array}$ \\
\hline $\mathbf{4 6 2}$ & 4.06 & 0.601 & 0.235 & 0.136 & 0.364 & 2.55 \\
\hline $\mathbf{1 1 0 0}$ & 5.05 & 0.578 & 0.106 & 0.163 & 0.395 & 2.55 \\
\hline $\mathbf{1 8 5 0}$ & 8.36 & 0.47 & 0.082 & 0.203 & 0.503 & 2.57 \\
\hline
\end{tabular}

\subsection{Studied Variables}

The experimental program was planned to study the effects of stirring speed, solid-to-liquid ratio, temperature, acid type and concentration, and particle size. To decrease the effect of the diffusion through the boundary layer, stirring speed was increased from a low value, $700 \mathrm{rpm}$, which is sufficient to suspend freely the largest particles, to a high value, $1000 \mathrm{rpm}$. Experiments were performed at three temperatures 25, 35 and $45^{\circ} \mathrm{C}$, which is a suitable range, because Wadi Araba is a hot region in Jordan, and its climatic conditions are generally of low rainfall, mild winters and hot summers . The temperature reaches $40{ }^{\circ} \mathrm{C}$ in summer, so, if a copper leaching plant is established in the Wadi Araba area, and since most leaching processes are done near climatic temperatures, the kinetics data obtained at the chosen temperature range will be useful in operating and designing the plant. Hydrochloric acid was used as the main lixiviant in this study. In addition, for comparative purposes, some experiments were done using sulfuric acid solution.

\subsection{Experimental Procedure}

For a given experiment, one liter of acid solution (hydrochloric or sulfuric acid) is prepared with the desired normality then poured into the reaction vessel. The water in the heating bath was heated and stirred until the desired constant temperature was attained. When the reaction solution 
equilibrated at the desired temperature the solution in the reaction vessel was agitated, at the desired stirring speed. The sample of the ore of the required particle size, was accurately weighted, using Sartorius model 2007MP balance, and quantitatively transferred into the reactor, at the same time of pressing the start button of a stopwatch.

Samples from the reactor were removed at different predetermined times using sampling device. Each sample was poured into a marked flask, stoppered and kept for copper analysis by atomic absorption technique. From the copper ion content in the sample solution, as measured in ppm, the total copper ion content in the reaction solution was calculated taking into consideration the change in the volume of the reaction solution as successive samples were withdrawn. The total copper ion content in the reactor at any particular instant during the reaction, divided by the amount of copper in the ore, initially charged into the reactor, gave the copper dissolution percentage $\left(\mathrm{X}_{\mathrm{Cu}}\right)$. In some experiments and for chosen sample solutions, analysis was done for other elements: Manganese Mn, Aluminum Al, Iron $\mathrm{Fe}$ and Calcium Ca. The results of these measurements will be used in the acid consumption calculation.

\section{RESULTS AND DISCUSSIONS}

Five variables and their effects on the rate of leaching of copper from its copper ores were taken into consideration, and are reported below.

\subsection{Acid Consumption}

During the analysis, some samples were analyzed for $\mathrm{Cu}, \mathrm{Mn}$, $\mathrm{Ca}, \mathrm{Fe}$, and $\mathrm{Al}$, at different intervals of time. These results, Tables 2 and 3, were used to estimate $\mathrm{HCl}$ acid consumption, since calculations based on measuring the $\mathrm{pH}$ of the solution cannot be used because the variations in the $\mathrm{pH}$ of the solution are very small and are within the precision of the measuring instrument. An approximate acid consumption was determined from the concentration of different elements in the reaction solution. Some of the elements which are found in the copper ores are in the form of $\mathrm{Cu}^{+2}, \mathrm{Mn}^{+4}, \mathrm{Ca}^{+2}, \mathrm{Al}^{+3}$, and $\mathrm{Fe}^{+3}$, so when these elements react with $\mathrm{HCl}$ to form the corresponding chlorides, each mole of $\mathrm{Cu}^{+2}$ or $\mathrm{Ca}^{+2}$ needs 2 moles of $\mathrm{HCl}$, while one mole of $\mathrm{Mn}^{+4}$ needs 4 moles of $\mathrm{HCl}$ and each mole of either $\mathrm{Al}^{+3}$ or $\mathrm{Fe}^{+3}$ needs 3 moles of $\mathrm{HCl}$. Thus using the conversion for each of the above mentioned elements, acid consumption needed to react with each element can be calculated according to the following equation:

$$
H C l(g) \text { needed }=\frac{F C \times M O \times M Y O \times S L \times M w t ~ H C l}{M w t Y}
$$

where: FC is the percentage dissolution of $\mathrm{Y}, \mathrm{MO}$ is the mass of the ore in the reactor, MYO is the mass fraction of element $\mathrm{Y}$ in the ore, SL is acid to element $\mathrm{Y}$ mole ratio, and Mwt is the molecular weight.
Using the values presented in Table 1 and Table 2, a sample calculation for the acid consumption at $120 \mathrm{~min}$ reaction time under the reaction conditions indicated in Table 2 can be written as:

$\mathrm{HCl}$ needed for

$C u=\frac{0.7568 \times 1 \times 0.0406 \times 2 \times 35.5}{63.5}=0.0343 \mathrm{~g}$

$M n=\frac{0.0585 \times 1 \times 0.006 \times 4 \times 35.5}{54.9}=9.09 \times 10^{-4} \mathrm{~g}$

$C a=\frac{0.3267 \times 1 \times 0.00235 \times 2 \times 35.5}{40}=1.36 \times 10^{-3} \mathrm{~g}$

$F e=\frac{0.313 \times 1 \times 0.00136 \times 3 \times 35.5}{55.8}=8.1 \times 10^{-4} \mathrm{~g}$

$A l=\frac{0.4955 \times 1 \times 0.00364 \times 3 \times 35.5}{27}=7.11 \times 10^{-3} \mathrm{~g}$

Total $\mathrm{HCl}$ consumed $=0.0343+9.09 \times 10^{-4}+1.36 \times$ $10^{-3}+8.1 \times 10^{-4}+7.11 \times 10^{-3}=0.0458 \mathrm{~g}$

Two experiments were done to determine the acid consumption, Tables 2 and 3. During the maximum leaching time used in the present study, $2 \mathrm{hr}$, the acid consumption was about $0.09 \mathrm{~g}$ of $\mathrm{HCl}$. This acid consumption, Table 3, occurred at the most severe reaction conditions, namely: 45 ${ }^{\circ} \mathrm{C}$ and $0.2 \mathrm{~N} \mathrm{HCl}$. Knowing that the masses of the concentrated $\mathrm{HCl}$ of concentrations $0.05,0.10$, and $0.2 \mathrm{~N}$ charged into the reactor is $5.154,10.307$, and $20.614 \mathrm{~g}$, respectively, it can be concluded that the percent of the acid consumed is very low and does not exceed $1 \%$. Accordingly the reaction environment around the solid particles in the reactor during the reaction time is almost uniform.

In their study, Lui et al. [25] used dilute sulfuric acid to recover copper from coper oxide ore by heap leaching. The results show that heaps of $-40 \mathrm{~mm}$ ore leached for 68 days produced a copper leaching rate of up to $85.8 \%$ and the consumption of the dilute sulfuric acid was $24.2 \mathrm{~kg}$ per tonore. In another study, Araya et al.[26] reported dilute $\mathrm{H}_{2} \mathrm{SO}_{4}$ consumption of $122.6 \mathrm{~kg} /$ tone of copper ore, the ore was crushed and milled to a particle size below $150 \mu \mathrm{m}$ in this study. Azmayandeh et al. [27] investigated the acid consumption in a heap leaching process to recover copper from low grade oxide-sulfide copper ore. The authors reported that a weak sulfuric acid consumption of up to $54 \mathrm{~kg}$ per ton of ore was needed to recover about $59 \%$ of the copper exist in the ore. 
Table 2 : Elements percentage dissolution at $45^{\circ} \mathrm{C}, 1000 \mathrm{rpm}, 1.0$ $\mathrm{g} / \mathrm{L}$ solid to liquid ratio, $0.05 \mathrm{~N} \mathrm{HCl}$, and $462 \mu \mathrm{m}$ particles

\begin{tabular}{|l|c|c|c|c|c|c|}
\hline $\begin{array}{c}\text { Time } \\
(\mathbf{m i n})\end{array}$ & $\begin{array}{c}\mathbf{X}_{\mathbf{C u}} \\
\%\end{array}$ & $\begin{array}{c}\mathbf{X}_{\mathbf{M n}} \\
\%\end{array}$ & $\begin{array}{c}\mathbf{X}_{\mathbf{C a}} \\
\%\end{array}$ & $\begin{array}{c}\mathbf{X}_{\mathbf{F e}} \\
\%\end{array}$ & $\begin{array}{c}\mathbf{X}_{\mathbf{A l}} \\
\%\end{array}$ & $\begin{array}{c}\text { Acid } \\
\text { consumed } \\
(\mathbf{g})\end{array}$ \\
\hline $\mathbf{1 5}$ & 50.82 & 2.07 & 18.29 & 8.43 & 19.94 & 0.028 \\
\hline $\mathbf{4 0}$ & 68.76 & 3.6 & 25.2 & 17.28 & 30.99 & 0.0373 \\
\hline $\mathbf{1 2 0}$ & 75.68 & 5.85 & 32.67 & 31.29 & 49.55 & 0.0458 \\
\hline
\end{tabular}

Table 3 : Elements percentage dissolution at $45^{\circ} \mathrm{C}, 1000 \mathrm{rpm}, 1.0$ $\mathrm{g} / \mathrm{L}$ solid to liquid ratio, $0.2 \mathrm{~N} \mathrm{HCl}$, and $1850 \mu \mathrm{m}$ particles

\begin{tabular}{|l|c|c|c|c|c|c|}
\hline $\begin{array}{c}\text { Time } \\
(\mathbf{m i n})\end{array}$ & $\begin{array}{c}\mathbf{X}_{\mathbf{C u}} \\
\%\end{array}$ & $\begin{array}{c}\mathbf{X}_{\mathbf{M n}} \\
\%\end{array}$ & $\begin{array}{c}\mathbf{X}_{\mathbf{C a}} \\
\%\end{array}$ & $\begin{array}{c}\mathbf{X}_{\mathbf{F e}} \\
\%\end{array}$ & $\begin{array}{c}\mathbf{X}_{\mathbf{A l}} \\
\%\end{array}$ & $\begin{array}{c}\text { Acid } \\
\text { consumed } \\
(\mathbf{g})\end{array}$ \\
\hline $\mathbf{1 5}$ & 32.35 & 3.25 & 40.76 & 6.12 & 34.74 & 0.0395 \\
\hline $\mathbf{4 0}$ & 53.04 & 4.6 & 45.85 & 20.19 & 48.4 & 0.0608 \\
\hline $\mathbf{1 2 0}$ & 63.71 & 6.3 & 51.89 & 42.76 & 54.43 & 0.0871 \\
\hline
\end{tabular}

\subsection{Stirring Speed Effect}

It is known that for particles of different sizes reacting under similar conditions, the importance of diffusion effects through the boundary layer film in controlling the overall rate of reaction is reduced as the particles of unchanging size are increased in size[9]. Accordingly the smallest particles were used in this investigation to determine the minimum stirring speed beyond which the effect of film boundary layer surrounding the ore particles can be neglected in determining the overall rate of leaching.

The effect of the impeller speed was studied, using particle size of $462 \mu \mathrm{m}$ of ore No. 1, and under the experimental conditions: temperature of $25{ }^{\circ} \mathrm{C}, \mathrm{HCl}$ concentration of $0.1 \mathrm{~N}$ and solid to liquid ration of $1.0 \mathrm{~g} / \mathrm{L}$. Stirring speed was varied from 700 to $1000 \mathrm{rpm}$ and the results are shown in Figure 3.To check for a significant difference between conversions at different stirring speeds, a statistical test, Wilcoxon signed rank test [28], has been implemented. The average values of copperconversions at stirring speeds of 700, 900, and 1000 rpm, used in this analysis, are show in Table 4.

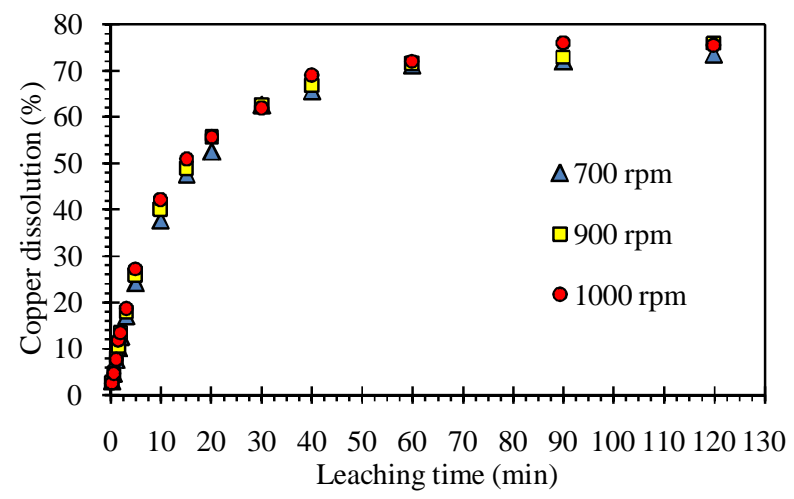

Figure 3 : Copper dissolution as a function of stirring speed at $25{ }^{\circ} \mathrm{C}$; particle size $462 \mu \mathrm{m}$ of ore; solid/liquid ratio $1.0 \mathrm{~g} / \mathrm{L}$ and $0.1 \mathrm{~N} \mathrm{HCl}$.
Let $\Delta_{1}$ be the difference between pairs of conversions at stirring speeds of 900 and $700 \mathrm{rpm}$, and $\Delta_{2}$ be the difference between pairs at stirring speeds of 1000 and $900 \mathrm{rpm}$, as shown in Table 4. Now, $\Delta_{1}$ and $\Delta_{2}$ are ranked according to their absolute values, with the smallest rank given to smallest difference value. If there is no difference in the degree of conversion when stirring speed vary from 700 to $900 \mathrm{rpm}$ or from 900 to $1000 \mathrm{rpm}$, the sum of the positive ranks should be nearly equal numerically to the sum of the negative ranks. The total sum of all ranks for $\mathrm{n}$ paired observations is given as [28]:

$$
\text { Sumofallranks }=1+2+\cdots+n=\frac{n(n+1)}{2}
$$

Now, for the $\Delta 1$ sample:

$$
\text { Sumofallranks }=\frac{15(16)}{2}=120
$$

And, hence, the expected sum of either positive or negative signed ranks is $120 / 2=60$.

The observed sum of negative ranks, Table 4 , is $\sum \mid$-veranks $\mid=2+3=5$ and the observed sum of positive ranks is $\sum \mid+$ veranks $\mid=4.5+4.5+7.5+7.5+12+$ $13+11+15+1+10+6+9+14=115$

To check for a significant difference, the absolute value of the smaller sum of ranks, that is, 5 should be compared to the critical value of the smaller sum of signed ranks (R) given in Table VII [28]; this is for $\mathrm{n}=15$ :

$\mathrm{R}=25$ at $5 \%$ level of significance, $\mathrm{R}=20$ at $2 \%$ level of significance, and $\mathrm{R}=16$ at $1 \%$ level of significance

Since $5<16<20<26$, the null hypothesis can be rejected, at the corresponding significance level, and we can infer that there is a difference in the degree of conversion when stirring speed is increased from 700 to $900 \mathrm{rpm}$.

For the $\Delta_{2}$ sample:

$$
\text { Sumofallranks }=\frac{14(15)}{2}=105
$$

And, hence, the expected sum of either positive or negative signed ranks is $105 / 2=52.5$.

From Table $4, \sum \mid$-veranks $\mid=3+4+8+7=22$ and the observed sum of positive ranks is $\sum \mid+$ veranks $\mid=10+1+$ $6+9+11.5+11.5+2+13+5+4=83$

To check for a significant difference, the absolute value of the smaller sum of ranks, that is, 22 should be compared to the critical value of the smaller sum of signed ranks ( R) given in Table VII [28]; this is for $\mathrm{n}=14$ :

$\mathrm{R}=21$ at $5 \%$ level of significance, $\mathrm{R}=16$ at $2 \%$ level of significance, and $\mathrm{R}=13$ at $1 \%$ level of significance

Since $22>21>16>13$, the null hypothesis cannot be rejected at the indicated significance level, and we can infer that there is no significance difference in the degree of 
conversion when stirring speed is increased from 900 to 1000 rpm.

Table 4 : Statistical analysis for stirring speed effect

\begin{tabular}{|c|c|c|c|c|c|c|c|}
\hline $\mathbf{P}$ & $\begin{array}{c}X_{1} \text { at } \\
700 \\
\text { rpm }\end{array}$ & $\begin{array}{c}\mathrm{X}_{2} \text { at } \\
\mathbf{9 0 0} \\
\mathrm{rpm}\end{array}$ & $\begin{array}{l}X_{3} \text { at } \\
1000 \\
\text { rpm }\end{array}$ & $\begin{array}{c}\Delta_{1} \\
\mathbf{X}_{2}-\mathbf{X}_{1} \\
\end{array}$ & $\begin{array}{c}\Delta_{2} \\
\mathbf{X} 3-\mathbf{X}_{2} \\
\end{array}$ & $\begin{array}{l}\text { Rank } \\
\text { for } \Delta_{1} \\
\end{array}$ & $\begin{array}{l}\text { Rank } \\
\text { for } \Delta_{2}\end{array}$ \\
\hline 1 & 2.99 & 2.76 & 2.58 & -0.23 & -0.18 & -3 & -3 \\
\hline 2 & 4.65 & 4.6 & 4.6 & -0.05 & 0 & -2 & - \\
\hline 3 & 7.58 & 7.89 & 7.62 & 0.31 & -0.27 & 4.5 & -4 \\
\hline 4 & 10.12 & 10.43 & 11.89 & 0.31 & 1.46 & 4.5 & 10 \\
\hline 5 & 12.47 & 13.32 & 13.34 & 0.85 & 0.02 & 7.5 & 1 \\
\hline 6 & 17.14 & 17.99 & 18.6 & 0.85 & 0.61 & 7.5 & 6 \\
\hline 7 & 24.1 & 25.85 & 27.3 & 1.75 & 1.45 & 12 & 9 \\
\hline 8 & 37.77 & 40.05 & 42.03 & 2.28 & 1.98 & 13 & 11.5 \\
\hline 9 & 47.66 & 48.88 & 50.86 & 1.22 & 1.98 & 11 & 11.5 \\
\hline 10 & 52.57 & 55.55 & 55.6 & 2.98 & 0.05 & 15 & 2 \\
\hline 11 & 62.52 & 62.53 & 61.88 & 0.01 & -0.65 & 1 & -8 \\
\hline 12 & 65.6 & 66.65 & 68.99 & 1.05 & 2.34 & 10 & 13 \\
\hline 13 & 71.16 & 71.52 & 72.09 & 0.36 & 0.57 & 6 & 5 \\
\hline 14 & 72.01 & 72.89 & 75.86 & 0.88 & 2.97 & 9 & 14 \\
\hline 15 & 73.54 & 75.95 & 75.32 & 2.41 & -0.63 & 14 & -7 \\
\hline
\end{tabular}

From this analysis, it can be inferred that there is a significant difference in the degree of conversion when stirring speed is increased from 700 to $900 \mathrm{rpm}$, but increasing the stirring speed from 900 to $100 \mathrm{rpm}$ does not produce a significant difference in the conversion, using the $5 \%$ significance level. Based on the above findings and in order to eliminate, as much as possible, the influence of diffusion through the boundary layer in controlling the reaction rate, all subsequent leaching rate measurements were done using the high stirring speed of $1000 \mathrm{rpm}$.

\subsection{Solid to Liquid Ratio Effect}

Four runs were done to investigate the effect of solid to liquid ratio on leaching rate. These runs were conducted under the conditions: $\mathrm{HCl}$ concentration fixed at $0.1 \mathrm{~N}$, temperature at $25{ }^{\circ} \mathrm{C}$, stirring speed of $1000 \mathrm{rpm}$, and $462 \mu \mathrm{m}$ particle size, the solid to liquid ratio varied from $1 \mathrm{~g} / \mathrm{L}$ to $4 \mathrm{~g} / \mathrm{L}$. Figure 4 shows the results and it can be seen that increasing the solid to liquid ratio results in a decrease in the conversion. This reduction in the rate of leaching of copper may be attributed to one or both of the following reasons:

a) Increasing the solid to liquid ratio results in an increased acid consumption corresponding to a given fixed percentage recovery of copper. Thus, experiments conducted at a high solid to liquid ratio and fixed initial acid concentration are effectively conducted in a lower acid concentration environment, compared to experiments conducted at low solid to liquid ratio. This should results in lowering the leaching rate since as will be shown later, that decreasing the concentration of the acid medium in which the reaction takes place, results in decreased rate of leaching.

b) For the same degree of conversion of copper and under the same experimental conditions, the concentration in the acid medium of the reacted gangue materials are increased as the solid to liquid ratio is increased, and may adversely influence the rate of recovery of copper. Such interfering effect of gangue material ions $\left(\mathrm{Al}^{3+}, \mathrm{Mg}^{2+}\right.$, $\mathrm{Fe}^{2+}$ and $\mathrm{Fe}^{3+}$ ) has been investigated and shown to affect the rate of leaching of copper ores with sulfuric acid [29].

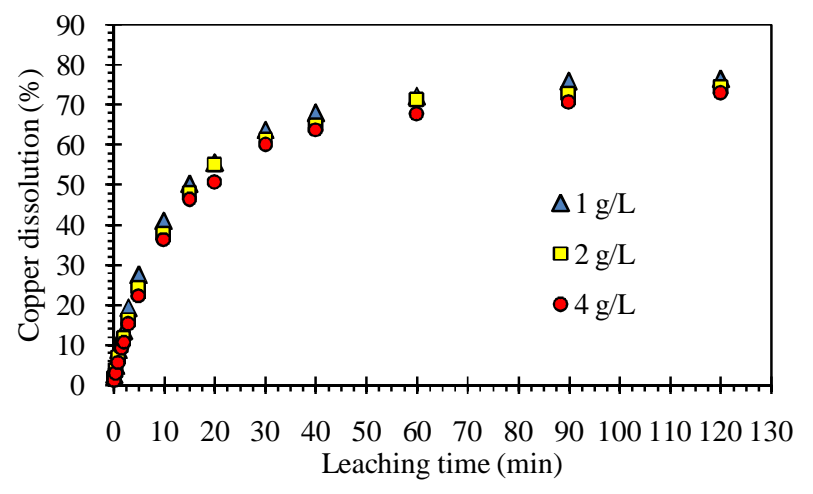

Figure 4: Copper dissolution as a function of $\mathrm{S} / \mathrm{L}$ ratio at 25 ${ }^{\circ} \mathrm{C}, 100 \mathrm{rpm}, 462 \mu \mathrm{m}$ particle size, and $0.1 \mathrm{~N} \mathrm{HCl}$

In order to minimize the plausible undesirable by-products effect and to achieve one of the assumptions of the models under investigation, namely, that each solid particle issurrounded by a uniform and constant concentration of reagent at any instant [9],the majority of runs were conducted using $1.0 \mathrm{~g} / \mathrm{L}$ solid to liquid ratio.

A solid to liquid ratio of $100 \mathrm{~g} / \mathrm{L}$ was used by Lundstrom et al. [30] when they studied sulfuric acid leaching for capturing copper from copper rich convertor slag, a copper rich process solution with iron as the main impurity metal was obtained as a result of the leaching process. Yang et al. [31] reported a solid to liquid ratio of 1 to $10 \mathrm{~g} / \mathrm{mL}$ to extract higher than 90 $\mathrm{wt} \%$ of copper from spent printed circuit boards using sulfuric acid. Compared with the current study; most available studies in literature used sulfuric acid rather than hydrochloric acid and the concentration used was dilute or weak acid while in this study up to $0.2 \mathrm{~N} \mathrm{HCl}$ is used.

\subsection{Temperature and Hydrochloric Acid Concentration Effects}

At various fixed temperatures the effect of increasing $\mathrm{HCl}$ concentration on the conversion were studied. Figures 5 and 6 show the influence of $\mathrm{HCl}$ concentration (lowest and highest) on copper dissolution at 25,35 , and $45{ }^{\circ} \mathrm{C}$, with $462 \mu \mathrm{m}$ particle size. It is clearly seen that increasing the leaching temperature eliminates the effect of the $\mathrm{HCl}$ concentration and the percentage of copper dissolution almost approaches same values by the end of the leaching time. Figure 7 reveals that at a given temperature, increasing the concentration of $\mathrm{HCl}$ results in an increase in the percentage of copper dissolution 
$\left(\mathrm{X}_{\mathrm{Cu}}\right)$ especially at low temperatures, while at higher temperatures the $\%$ of copper dissolution is high even at low $\mathrm{HCl}$ concentration. For a fixed concentration of $\mathrm{HCl}$, increasing the leaching temperature results in an increase in the $\%$ of copper dissolution $\left(\mathrm{X}_{\mathrm{Cu}}\right)$ and this can be depicted clearly at low acid concentration. At higher temperatures and high acid concentration the \% of copper dissolution values were almost close to each other by the end of the leaching time. So, temperature and concentration effects are complimentary.

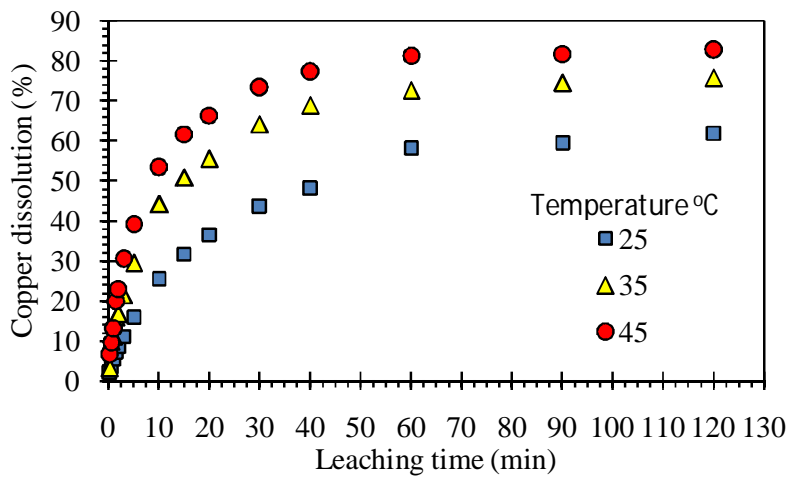

Figure 5 : Copper dissolution as a function of temperature at $0.05 \mathrm{~N} \mathrm{HCl}, 1000 \mathrm{rpm}, 1.0 \mathrm{~g} / \mathrm{L} \mathrm{S} / \mathrm{L}$ ratio, and $462 \mu \mathrm{m}$ particle size.

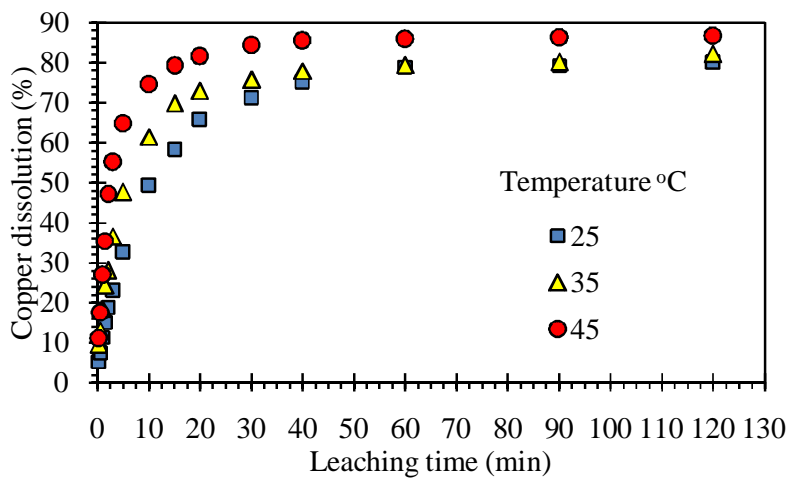

Figure 6 : Copper dissolution as a function of temperature at $0.2 \mathrm{~N} \mathrm{HCl}, 1000 \mathrm{rpm}, 1.0 \mathrm{~g} / \mathrm{L} \mathrm{S} / \mathrm{L}$ ratio, and $462 \mu \mathrm{m}$ particle size.

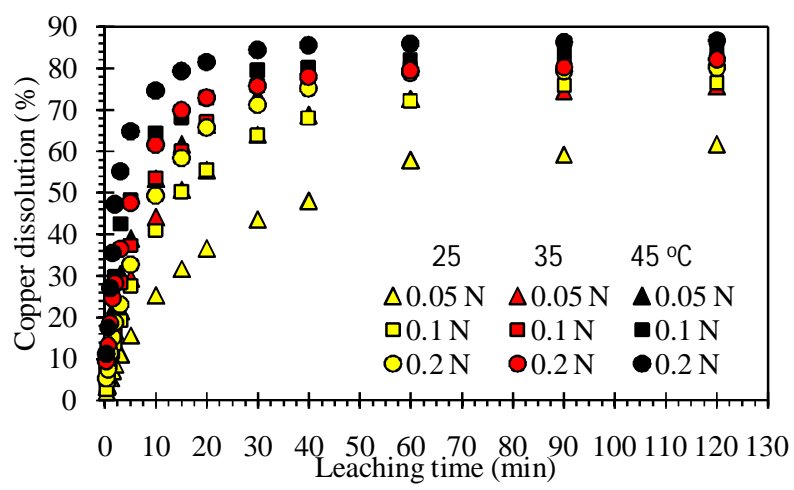

Figure 7 : Copper dissolution as a function of temperature and $\mathrm{HCl}$ concentration at $1000 \mathrm{rpm}, 1.0 \mathrm{~g} / \mathrm{L} \mathrm{S} / \mathrm{L}$ ratio, and 462 $\mu \mathrm{m}$ particle size.
In a recent study, Wang et al. [32] found that copper can be easily leached at ambient temperature from copper oxide minerals such as malachite and pseudo- malachite, only the bonded copper minerals were not leached at all at this temperature. Increasing temperature was favorable to the leaching of bonded copper minerals, and the dissolution of copper was mainly in isomorphism state at a temperature of $40{ }^{\circ} \mathrm{C}$. The leaching rate of copper in the adsorbed state was significantly accelerated with an increase in temperature to 60 ${ }^{\circ} \mathrm{C}$. And at $80{ }^{\circ} \mathrm{C}$, the isomorphic copper was completely leached, but leaving $11.2 \%$ adsorbed copper un-leached. By the end of leaching time of $240 \mathrm{~min}, 1.0 \mathrm{M} \mathrm{NaNO} 3,2.5 \mathrm{M}$ $\mathrm{H} 2 \mathrm{SO} 4$, and $\mathrm{S} / \mathrm{L}$ ratio=1:60, Nyamdelger et al. [33] found that copper dissolution was increased from $69.5 \%$ to $86.8 \%$ by raising the leaching temperature from $70^{\circ} \mathrm{C}$ to $90{ }^{\circ} \mathrm{C}$.

\subsection{Particle Size Effect}

For a fixed weight of particles, the effective surface area available for reaction increases and the diffusion path decreases as the particles are ground to finer size, the reaction will be fast and the leaching time will be small, while, for large particles the reaction will be slow and the leaching time will be large. Thus, the conversion increases inversely with particle size. This effect is demonstrated dramatically in Figures 8 to 10 , at various temperatures and $\mathrm{HCl}$ concentration. By the end of leaching time, copper dissolution was increased from $43 \%$ at $1850 \mathrm{~mm}$ to $80 \%$ at $462 \mathrm{~mm}$ when the leaching temperature was $25{ }^{\circ} \mathrm{C}$, i.e. increased by $86 \%$ as shown in Figure 8 . Figure 9, reveals that by increasing the reaction temperature to $45^{\circ} \mathrm{C}$, the difference in copper dissolution between 1850 and $462 \mu \mathrm{m}$ are noticeable but much smaller than the difference at $25{ }^{\circ} \mathrm{C}$ for the same particle size, i.e. increased by about $36 \%$.

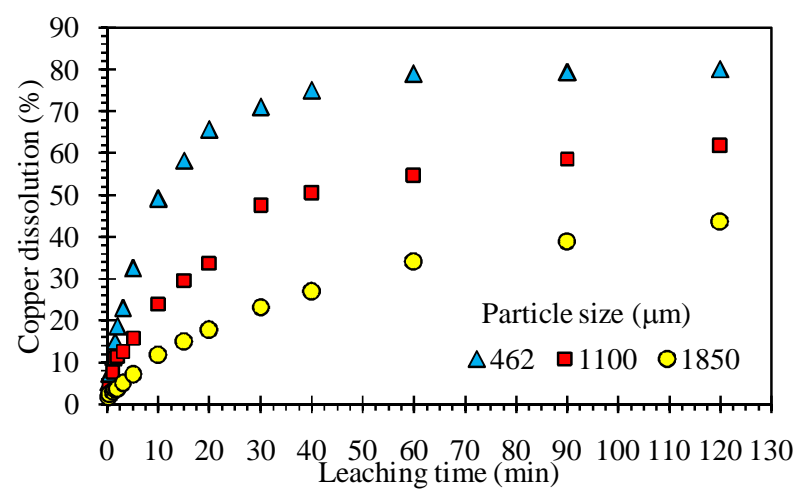

Figure 8: Copper dissolution as a function of reacted particle size at a temperature of $25{ }^{\circ} \mathrm{C}, 0.2 \mathrm{~N} \mathrm{HCl}, 1000 \mathrm{rpm}$, and 1.0 $\mathrm{g} / \mathrm{L} \mathrm{S} / \mathrm{L}$ ratio. 


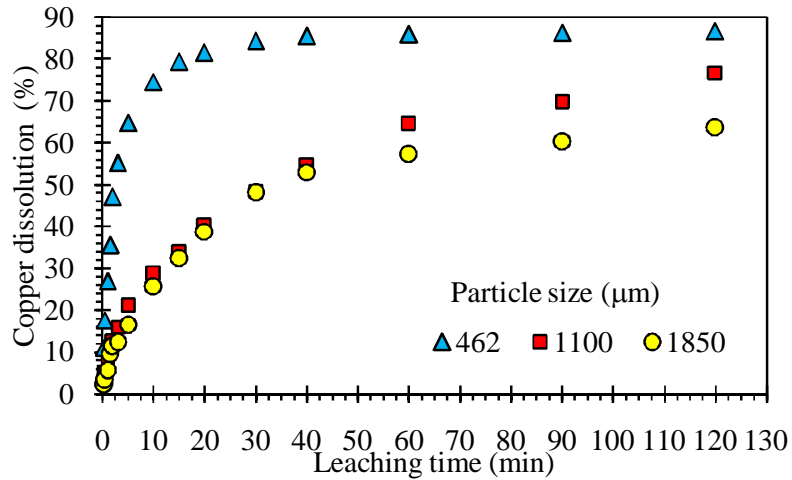

Figure 9 : Copper dissolution as a function of reacted particle size at a temperature of $45^{\circ} \mathrm{C}, 0.2 \mathrm{~N} \mathrm{HCl}, 1000 \mathrm{rpm}$, and 1.0 $\mathrm{g} / \mathrm{L} \mathrm{S} / \mathrm{L}$ ratio.

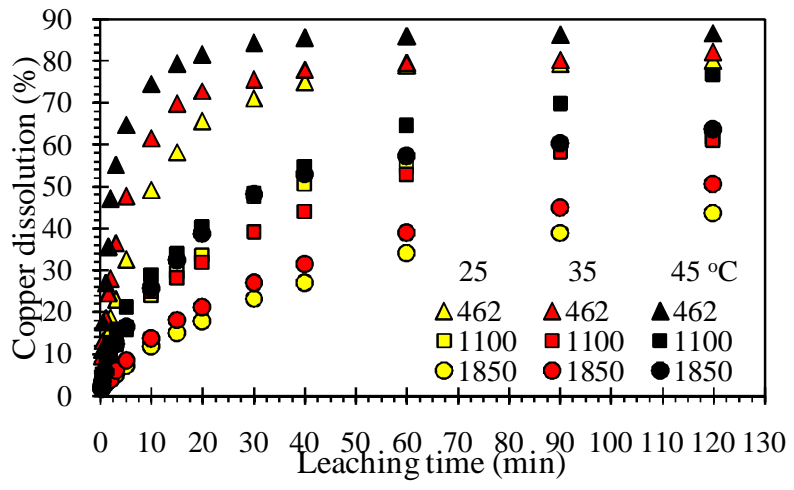

Figure 10 : Copper dissolution as a function of reacted particle size at different reaction temperatures and $0.2 \mathrm{~N} \mathrm{HCl}$, $1000 \mathrm{rpm}$, and $1.0 \mathrm{~g} / \mathrm{L} \mathrm{S} / \mathrm{L}$ ratio.

Nyamdelger et al. [33] reported that that the copper dissolution rate is highly dependent on the particle size, when the same leaching conditions were applied the dissolved copper increased from 60.58 to $90.3 \%$ by changing the particle size from $+74 \mathrm{~mm}-25.4 \mathrm{~mm}$. The effect of different particle sizes on the rate of the copper leaching was investigated by Zhou et al. [34]. The authors found that $89.27 \%$ of copper was extracted at $5-10 \mu \mathrm{m}$ while only while only $57.08 \%$ was extracted at $15-25 \mu \mathrm{m}$.

\subsection{Comparison between $\mathrm{HCl}$ and $\mathrm{H}_{2} \mathrm{SO}_{4}$ as a Lixiviant}

Figures 11 and 12 show a comparison between $\mathrm{HCl}$ and $\mathrm{H}_{2} \mathrm{SO}_{4}$ as leaching lixiviants. From these figures it is clearly seen that at the same operating conditions, $\mathrm{H}_{2} \mathrm{SO}_{4}$ gives slightly greater conversion than $\mathrm{HCl}$ at low temperature and low acid concentration. But the differences between the conversions become smaller as the temperature and acid concentration are increased and the ore particles become smaller. Cho et al. [35] investigated the influence of the acid type and concentration on the acid leaching process for Mongolian apatite-based ore containing rare-earth elements. Sulfuric, hydrochloric, and nitric acids were used in the study and it has been found that hydrochloric acid was the most effective leaching agent, leached more than $90 \%$ of rare-earth elements.

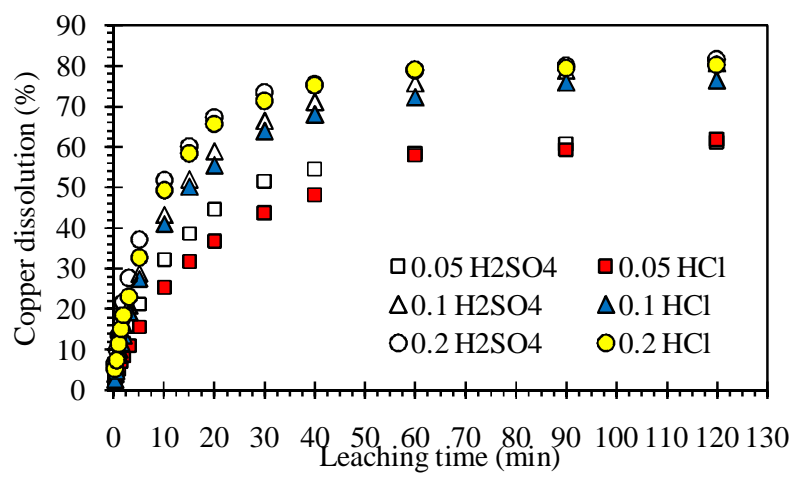

Figure 11: Comparison between $\mathrm{HCl}$ and $\mathrm{H}_{2} \mathrm{SO}_{4}$ as lixiviant at $25{ }^{\circ} \mathrm{C}, 462 \mu \mathrm{m}$ particle size, $1.0 \mathrm{~g} / \mathrm{L} \mathrm{S} / \mathrm{L}$ ratio, and 1000 rpm.

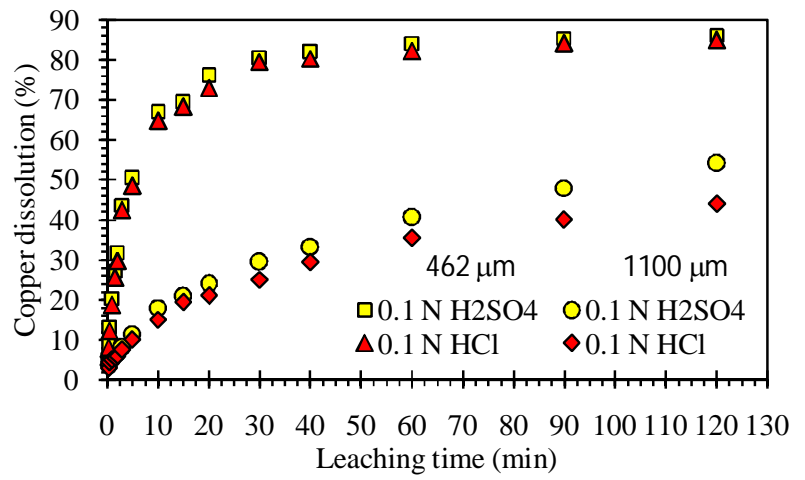

Figure 12 : Copper dissolution as a function oflixiviant and particle size at $45{ }^{\circ} \mathrm{C}, 1000 \mathrm{rpm}, 1.0 \mathrm{~g} / \mathrm{L} \mathrm{S} / \mathrm{L}$ ratio, and 462 $\mu \mathrm{m}$ particle size.

\section{CONCLUSIONS}

The rate of leaching of Jordanian copper ore using hydrochloric acid was found to increase with increasing temperature and acid concentration but decreases with increasing particle size. Stirring speed above $900 \mathrm{rpm}$ had slight effect on the percentage of copper dissolution. And thus the diffusion through the liquid film surrounding the ore particles under the operating conditions used in the present study can be neglected.

With the present condition of the study, it was found that hydrochloric acid consumed during the leaching time of 2 hours and using solid to liquid ratio of $1 \mathrm{~g} / \mathrm{L}$ does not exceed $1 \%$ of the initial acid poured into the batch reactor. Also, it has been found that at similar operating conditions and at low temperature and acid concentration, sulfuric acid gave slightly greater conversion than hydrochloric acid, but the difference between the conversions become smaller as the temperature and acid concentration are increased.

A copper dissolution $\%$ of about 87 can be achieved at a leaching temperature of $45{ }^{\circ} \mathrm{C}, 0.2 \mathrm{~N}$ hydrochloric acid, 1.0 $\mathrm{g} / \mathrm{L}$ solid to liquid ratio, $1000 \mathrm{rpm}$ stirring speed, and $462 \mu \mathrm{m}$ particle size, while a copper dissolution $\%$ of about 83 can be obtained by decreasing the normality of the acid to 0.05 and keeping all other operating parameters constant. Less than 10 
$\%$ reduction in the copper dissolution was obtained by decreasing the leaching temperature to $25{ }^{\circ} \mathrm{C}$ while keeping the other operating parameters fixed at $0.2 \mathrm{~N}, 1.0 \mathrm{~g} / \mathrm{L}$ solid to liquid ratio, $1000 \mathrm{rpm}$ stirring speed, and a particle size of 462 $\mu \mathrm{m}$.

\section{REFERENCES}

1. Y.P.Reddy, K.L. Narayana, M.K. Mallik. Electrochemical behaviour of different metals in Sodium Chloride solution, International Journal of Emerging Trends in Eng. Research, Vol. 7(11), pp.715-719, 2019. https://doi.org/10.30534/ijeter/2019/507112019

2. G.D. Richmond, D.B. Dreisinger. Processing of Copper Sulfide Ores by Autoclave Leaching Followed by Extraction and Electrowinning, Australian Patent 749257, 2002.

3. J. Marsden, B. Brewer, N. Hazen. Copper concentrate leaching developments by Phelps Dodge Corporation, Electrometallurgy and Environmental Hydrometallurgy, Vol. 2, Warrendale, pp.1429-1446, 2003. https://doi.org/10.1002/9781118804407.ch28

4. R.P. Hackl, D.B. Dreisinger, J.A. King. Effect of sulfur dispersing surfactants on the oxygen pressure leaching of chalcopyrite. Electrorefining and hydrometallurgy of copper, Vol 3, pp.559-578, 1995.

5. M.M. Hourn, D.W. Turner, I.R. Holzberger. Atmospheric Mineral Leaching Process, US Patent 5993635, 1999.

6. M. Irfan, M. Khan, W.A. Khan. Impact of homogeneous-heterogeneous reactions and non-Fourier heat flux theory in Oldroyd-B fluid with variable conductivity, Journal of the Brazilian Society of Mechanical Sciences and Engineering, Vol. 41, 135, 2019. https://doi.org/10.1007/s40430-019-1619-9

7. L.K. Doraiswamy and B.D. Kulkarni. Gas-solid noncatalytic reactions, Chapter 5, in Chemical Reaction and Reaction Eng., Dekker, New York, USA, 1987.

8. K.O. Bryden. Ammonium-Sulfate Leaching of Malachite. A Kinetic Study, Ph.D. Thesis, University of Utah, USA, 1980.

9. O. Levenspiel. Chemical Reaction Engineering, $2^{\text {nd }}$ Ed., John Wiely and Sons Inc., New York, USA, 1972.

10. J.M. Smith. Chemical Engineering Kinetics, $3^{\text {rd }}$ Ed., McGraw-Hill Book Co., New York, USA, 1981.

11. H. Eyring, K.J. Laidler, S. Glasstone. The Theory of Rtae Process, McGraw-Hill Book Co., New York, USA, 1941.

12. F. Habashi. Principles of Extractive Metallurgy, Vol. 1, Gordon and Breach, Science Publishers Inc., New York, USA, 1969.

13. A. Potysz, E.D. vanHullebusch, J. Kierczak, M. Grybos, P.N. Lens, G. Guibaud. Copper metallurgical slagscurrent knowledge and fate: a review. Critical Reviews in Environmental Science and Technology,45(22), pp.2424-2488, 2015.

https://doi.org/10.1080/10643389.2015.1046769

14. P.K. Gbor, V. Mokri, C.Q. Jia. Characterization of smelter slags. Journal of Environmental Science \& Health Part A, 35(2), pp.147-167, 2000.

https://doi.org/10.1080/10934520009376960

15. P. Sarfo, A. Das, G. Wyss, C. Young. Recovery of metal values from copper slag and reuse of residual secondary slag. Waste Manag., 70, pp.272-281, 2017. https://doi.org/10.1016/j.wasman.2017.09.024

16. M.M. Abu-Ajamieh, F.K. Bender, R.N. Eicher. Natural Resources in Jordan, Natural Resources Authority, Amman, Jordan, 1988.

17. BRGM group. Wadi Araba Copper Project-Synthetic Final Report, Natural Resources Authority, Amman, Jordan, 1980.

18. Seltrust Eng. Ltd. The Performance of the ilot Testwork and Cottage Plant Feasibility Study on Wadi Araba Copper Ores, Phase I, Testwork Final Report, Natural Resources Authority, Amman, Jordan, 1984.

19. B.W. Madsen, M.E. Wadsworth, R.D. Grover. Application of a Mixed Kinetics Model to the Leaching of Low Grade Copper Sulfide Ores, Trans. Soc. Min. Engrs., AIME, Vol. 258, pp.69-74, 1975.

20. B.R. Benner, R.J. Roman. Determination of the Effective Diffusivity of Hydrogen Ions in Copper Ore, Trans. Soc. Min. Engrs., AIME, Vol. 256, pp. 103, 1974.

21. C.B. Kuzmanovoska, F.A. Popska, A.N. Grizo. Leaching of Low-Grade Chalcocite-Covellite ore in Sulfuric Acid Solution by Percolation Application of the Moving Reaction Zone Model, Journal of the Serbian Chemical Society, Vol. 51(1), p.55, 1986.

22. M.F. Al-Sayyed. Leaching of Copper from Wadi Araba Jordanian Ore, M.Sc. Thesis, University of Jordan, Amman, Jordan, 1988.

23. Y. Mubarak. Hydrochloric Acid Leaching of Jordanian Copper Ores, M.Sc. Thesis, University of Jordan, Amman, Jordan, 1992.

24. W.L. McCabe, J.C. Smith, P. Harriott. Unit Operations of Chemical Engineering, $4^{\text {th }}$ Ed., McGraw-Hill Co., New York, USA, 1987.

25. M. Liu, J. Wen, G. Tan, G. Liu, B. Wu. Experimental studies and pilot plant tests for acid leaching of lowgradecopper oxide ores at the Tuwu Copper Mine, Hydrometallurgy, 165(2), pp.227-233, 2016. https://doi.org/10.1016/j.hydromet.2016.04.009

26. G. Araya, N. Toro, J. Castillo, D. Guzmán, A. Guzmán, P. Hernández, R.I. Jeldres, R. Sepúlveda. Leaching of Oxide Copper Ores by Addition of Weak Acid from Copper Smelters, Metals, Vol. 10, 627, 2020. https://doi.org/10.3390/met10050627

27. M. Azmayandeh, V. Aghazadeh, H. Abdollahi. Investigation of Affecting Parameters on Heap 
Leaching Performance and Reducing Acid Consumption of Low Grade Oxide-Sulfide Copper

Ore, International Journal of Mineral Processing and Extractive Metallurgy, 2(4), pp. 40-45,2017. https://doi.org/10.11648/j.ijmpem.20170204.11

28. J.B. Kennedy, A.M. Neville. Basic Statistical Methods for Engineers and Scientists, $3^{\text {rd }}$ Ed., Harper and Row, 1986.

29. A.M. Kunaev, B.B. Beisembaev, E.A. Kopylove, B.K. Kenzhaliev, G.A. Galiakberova. IR Spectroscopy of the Aqueous Phases in Copper Heap Leaching, Kompleksn Ispol'z Miner. Syr' ya, Vol. 9, p.57, 1985.

30. M.K. Khalid, J. Hamuyuni, V. Agarwal, J. Pihlasalo, M. Haapalainen, M. Lundstrom. Sulfuric acid leaching for capturing value from copper rich converter slag, Journal of Cleaner Production, 215, pp.1005-1013, 2019. https://doi.org/10.1016/j.jclepro.2019.01.083

31. H., Yang, J., Liu, J. Yang.Leaching copper from shredded particles of waste printed circuit boards. Journal of Hazardous Materials, 187(1-3), pp.393-400, 2011.

http://dx.doi.org/10.1016/j.jhazmat.2011.01.051.

32. G. Wang, Y. Liu, L. Tong, Z. Jin, G. Chen, H. Yang. Effect of temperature on leaching behavior of copper minerals with different occurrence states in complex copper oxide ores, Transactions of Nonferrous Metals Society of China, 29(10), pp.2192-2201, 2019.

33. T. Narangarav, Sh. Nyamdelger, G. Ariunaa, T. Azzaya, G. Burmaa. Dissolution behavior of copper concentrate in acidic media using nitrate ions, Mongolian Journal of Chemistry, Vol. 15(41), pp.79-84, 2014. https://doi.org/10.5564/mjc.v15i0.328

34. W. Zhou, K. Li, Y. Wang, L. Zhang, H. Cheng, H. Zhou, Influence of particle size on copper recovery from sulfide ore by the moderately thermophilic microorganisms, Metallurgical Research and Technology, Vol. 116 (1), 119, 2019. https://doi.org/10.1051/metal/2018118

35. R. Kim, H. Cho, K.N. Han, K. Kim, M. Mun. Optimization of Acid Leaching of Rare-Earth Elements from Mongolian Apatite-Based Ore, Minerals, 6(3), 63, 2016.

https://doi.org/10.3390/min6030063 